\title{
Posterior Part of the Ambient Cistern
}

National Cancer Institute

\section{Source}

National Cancer Institute. Posterior Part of the Ambient Cistern. NCI Thesaurus. Code C33373.

The dorsal portion of the subarachnoid cistern, located in the midbrain, that is continuous with the quadrigeminal cistern and connects with the interpeduncular cistern. 